УДК 69

DOI $10.21661 / \mathrm{r}-116915$

М.А. Гончарова, А.О. Проскурякова, И.В. Ламов, Н.А. Матченко, Г.С. Дедяев, Р.Р. Мирзабаев

ПРИМЕНЕНИЕ ПОЛИГОНАЛЬНОЙ ФОРМЫ ДЛЯ ИЗДЕЛИЙ НА ОСНОВЕ ДРЕВЕСНО-ЦЕМЕНТНЫХ КОМПОЗИТОВ НА ПРИМЕРЕ АРБОЛИТА

Аннотация: в статье рассматриваются изделия из арболита с применением полигональной формы, а также особенности состава арболитобетона. $B$ работе выделены положительные моменты применения высокоэффективного Суперпластификатора С-3 в технологии изготовления арболитовой смеси.

Ключевые слова: арболитобетон, паз-гребень, древесно-иементный композит, арболит, «LEGO» блок.

M.A. Goncharova, A.O. Proskuryakova, I.V. Lamov, N.A. Matchenko, G.S. Dedyaev, R.R. Mirzabaev

\title{
APPLICATION OF THE POLYGONAL FORM FOR PRODUCTS ON THE BASIS OF WOOD AND CEMENT COMPOSITES ON THE EXAMPLE OF WOOD CONCRETE
}

Abstract: the article describes products from wood concrete with application of a polygonal form and the features of structure of wood concrete as well. The authors have noted positive moments of highly efficient Superplasticizer C-3 implementation in the technology of wood concrete mixture manufacture.

Keywords: wood concrete, groove crest, wood and cement composite, wood concrete, «LEGO»block.

Необходимость в высококачественном, недорогом, быстровозводимом и долговечном жилье существовала уже давно, и будет существовать до этих пор, пока существует человечество. В последнее время, к отмеченным ранее свой- 
ствам здания все больше прибавляются такие, как экологичность, воздухопроницаемость, энергоэффективность. Невзирая на множество различных стандартных решений, и разнообразие строительных материалов, подбор наилучшего материала до сих пор остается проблемой [1].

Всем этим качествам соответствует древесно-цементный композит - арболит.

В строительстве применяются изделия из арболита в виде массивных крупноразмерных блоков. Основным минусом для любых крупноразмерных блоков является наличие, так называемых, «мостиков холода». Для их устранения можно использовать изделия полигональной формы.

Полигональная форма (далее система «паз-гребень») запроектирована для 3-х видов блоков. Необходимость такой номенклатуры объясняется тем, что форма блока имеет множество выступающих ровных граней и поверхностей, и при монтаже конструкции некоторые из них нужно было бы спиливать (арболит легко пилится ножовкой по дереву), и в углах сооружения не удалось бы избежать мостов холода.

Вид стенового блока представлен на рисунке 1.

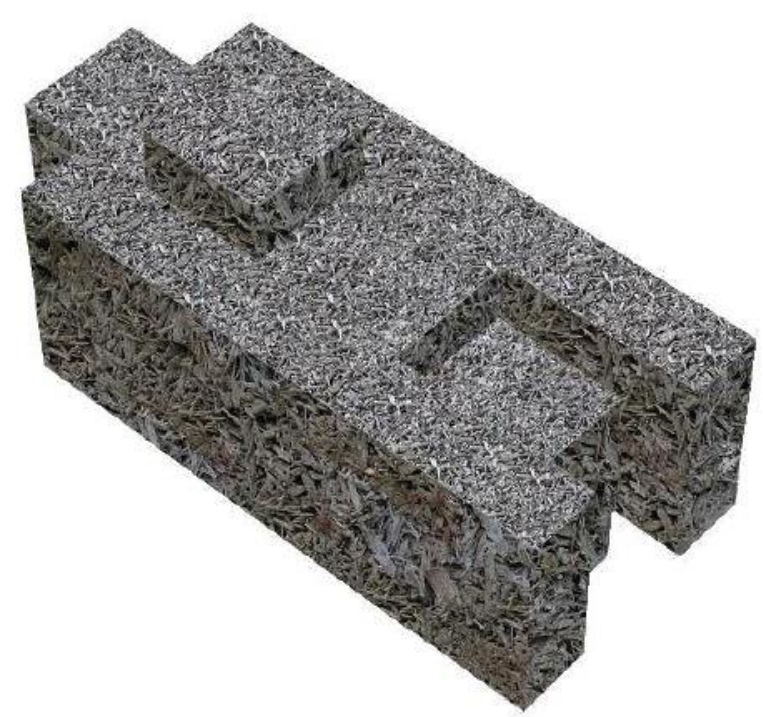

Рис. 1. Стеновой арболитовый блок «LEGO»

Угловой арболитовый блок 1 типа представлен на рисунке 2. 


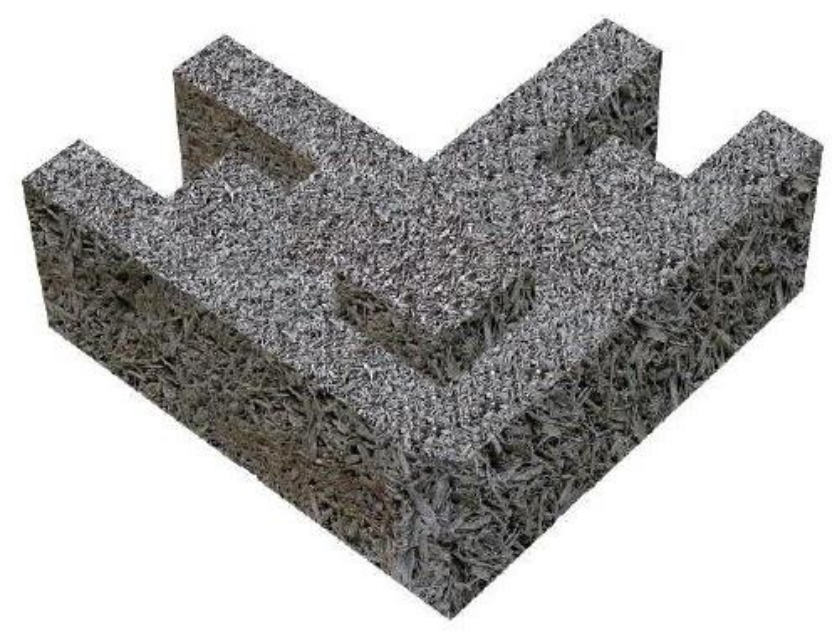

Рис. 2. Угловой арболитовый блок «LEGO» тип 1

Угловой арболитовый блок 2 типа представлен на рисунке 3.

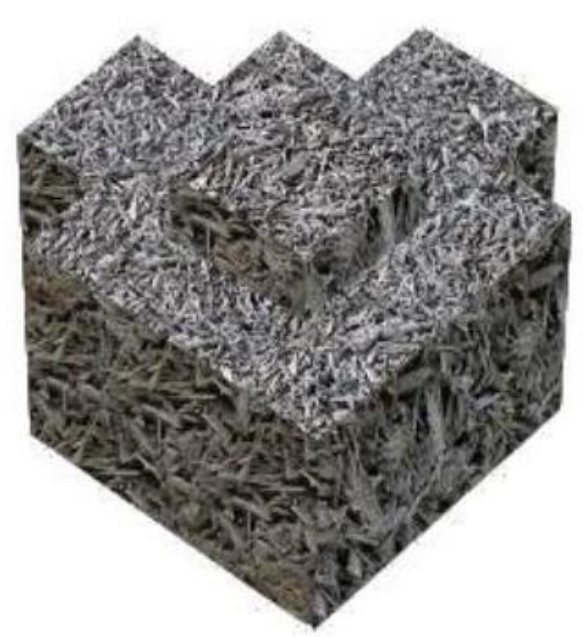

Рис. 3. Угловой арболитовый блок «LEGO» тип 2

Запроектированная полигональная форма позволяет сократить количество кладочного раствора, а также исключает появление мостов холода в конструкции.

Однако из-за неоднородной структуры арболитобетона, при производстве сложно получить стабильную, равномерно распределенную по всей опалубке смесь. Для этого в состав арболита вводятся химически-активные добавки.

Для создания арболитового блока полигональной формы с системой паз гребень (по принципу конструктора «LEGO») для лучшего заполнения формы-опалубки используется суперпластфикатор-С3 (ТУ 5745-001-97474489-2007) [2]. 
Обычно, данная химически-активная добавка используется в тяжелых бетонах для увеличения текучести бетонной смеси более чем в 5 раз, повышения прочности изделия, улучшения структуры бетона. В арболитовом же блоке полигональной формы добавка необходима для равномерного заполнения всего пространства опалубки, тем самым затвердевший, конечный продукт получается правильной формы, углы и грани ровные, равномерные, уменьшается усадка смеси.

Следует отметить, что все вышесказанное справедливо при соблюдении всех норм и требований, при производстве арболита.

Таким образом, применение суперпластификатора С-3 позволяет получить арболитовые блоки с точными геометрическими размерами для снижения расхода кладочного раствора. А благодаря полигональной форме обеспечивается максимальная теплозащита здания.

Однако, несмотря на вышеперечисленные характеристики изделий из арболита, необходимо их улучшение путем введения химических добавок в состав композиционного материала. Основными показателями для любого строительного материала являются прочность, теплопроводность и морозостойкость. Также немаловажным фактором является скорость набора прочности арболитобетона.

Очевидным является тот факт, что основными показателями увеличения прочности арболита является несколько факторов: внесение специальных химических добавок (ускорители твердения, замедлители твердения и другие), рационально подобранная смесь, замена основных сырьевых материалов. Подробно остановимся на подборе смеси и сырьевых материалах.

В качестве органического наполнителя может применяться: измельчённая древесина из отходов лесозаготовок, лесопиления, деревообработки хвойных пород (ель, сосна, пихта), размеры которых находятся в установленном диапазоне, в соответствии с ГОСТ 19222-84 «Арболит и изделия из него. Общие технические условия».

Размеры органического наполнителя не должны превышать:

- по ширине - 10 мм; 
- по длине - 40 мм;

- по толщине - 5 мм.

Наполнитель в бетоне занимает до $90 \%$ от общего объема изделия и скрепляется вяжущим веществом. Применяемый наполнитель влияет на технологические свойства и качество затвердевшего изделия. Правильно подобранные наполнители позволяют получать экономичный арболитобетон с минимальным расходом вяжущего вещества.

Содержание примесей коры в применяемой древесине не должно превышать $10 \%$, а хвои - не более $5 \%$ по массе к сухой смеси заполнителя.

Кроме этого, содержание в органическом заполнителе водорастворимых веществ не должно превышать $2 \%$ по массе.

Применяемые органические заполнители не должны иметь признаков гнили, плесени, инородных материалов (глин, грунта), а в зимнее время быть безо льда и снега.

Цемент используется производства ЗАО «Липецкцемент», который соответствует ГОСТ 31108-2003 «Цементы общестроительные. Технические требования». Химический и минералогический составы клинкера представлены в таблице 1.

Таблица 1

Химический и минералогический составы клинкера ЦЕМ I 42,5 H

\begin{tabular}{|c|c|}
\hline Показатели & Значение \\
\hline \multicolumn{1}{|c|}{ 1. Химический состав клинкера, \% } \\
\hline $\mathrm{CaO}$ & $66,20 \pm 0,20$ \\
$\mathrm{SiO}_{2}$ & $21,70 \pm 0,03$ \\
$\mathrm{Al}_{2} \mathrm{O}_{3}$ & $5,10 \pm 0,20$ \\
$\mathrm{Fe}_{2} \mathrm{O}_{3}$ & $4,10 \pm 0,10$ \\
$\mathrm{MgO}$ & $1,90 \pm 0,10$ \\
$\mathrm{SO}_{3}$ & $0,14 \pm 0,01$ \\
\hline \multicolumn{2}{|c|}{$0,54 \pm 0,05$} \\
\hline Щелочные оксиды в пересчете на $\mathrm{Na}_{2} \mathrm{O}$ & $65,0 \pm 2,0$ \\
\hline 2. Минералогический состав клинкера, \% \\
\hline $\mathrm{C}_{3} \mathrm{~S}$ & $13,0 \pm 2,0$ \\
$\mathrm{C}_{2} \mathrm{~S}$ & $6,5 \pm 0,5$ \\
$\mathrm{C}_{3} \mathrm{~A}$ & $12,4 \pm 0,4$ \\
$\mathrm{C}_{4} \mathrm{AF}$ &
\end{tabular}


В качестве химических добавок используется для ускорения твердения: хлорид кальция (ХК) по ГОСТ 450-77 «Кальций хлористый технический. Технические условия».

По физико-механическим характеристикам хлористый кальций соответствует нормам, указанным в таблице 2.

Таблица 2

Физико-химические показатели хлористого кальция

\begin{tabular}{|c|c|c|c|c|}
\hline \multirow[b]{2}{*}{ Наименование показателя } & \multicolumn{2}{|c|}{ Кальцинированный } & \multirow{2}{*}{$\begin{array}{c}\text { Гидратирован- } \\
\text { ный }\end{array}$} & \multirow[b]{2}{*}{ Жидкий } \\
\hline & $\begin{array}{c}\text { Высший } \\
\text { сорт }\end{array}$ & 1-й сорт & & \\
\hline 1. Внешний вид & \multicolumn{2}{|c|}{$\begin{array}{l}\text { Порошок или гранулы } \\
\text { белого цвета }\end{array}$} & $\begin{array}{l}\text { Чешуйки или } \\
\text { гранулы белого } \\
\text { или серого } \\
\text { цвета }\end{array}$ & $\begin{array}{l}\text { Раствор желто- } \\
\text { вато-серого или } \\
\text { зеленоватого } \\
\text { цвета прозрач- } \\
\text { ный или с лег- } \\
\text { кой мутью }\end{array}$ \\
\hline $\begin{array}{l}\text { 2. Массовая доля хлори- } \\
\text { стого кальция, \%, не менее }\end{array}$ & 96,5 & 90 & 80 & 35 \\
\hline $\begin{array}{l}\text { 3. Массовая доля магния в } \\
\text { пересчете на } \mathrm{MgCl} 2, \% \text {, не } \\
\text { более }\end{array}$ & 0,5 & 0,5 & Не нормируется & Не нормируется \\
\hline $\begin{array}{l}\text { 4. Массовая доля прочих } \\
\text { хлоридов, в том числе } \\
\mathrm{MgCl} 2, \text { в пересчете на } \mathrm{NaCl}, \\
\%, \text { не более }\end{array}$ & 1,5 & $\begin{array}{l}\text { Не норми- } \\
\text { руется }\end{array}$ & 5,5 & 3 \\
\hline $\begin{array}{l}\text { 5. Массовая доля железа, } \\
(\mathrm{Fe}), \%, \text { не более }\end{array}$ & 0,004 & То же & Не нормируется & Не нормируется \\
\hline $\begin{array}{l}\text { 6. Массовая доля не раство- } \\
\text { римого в воде остатка, \%, не } \\
\text { более }\end{array}$ & 0,1 & 0,5 & 0,5 & 0,15 \\
\hline $\begin{array}{l}\text { 7. Массовая доля сульфатов } \\
\text { в пересчете на сульфат-ион, } \\
\%, \text { не более }\end{array}$ & 0,1 & $\begin{array}{l}\text { Не норми- } \\
\text { руется }\end{array}$ & 0,3 & Не нормируется \\
\hline
\end{tabular}

Для образования плёнки на поверхности органических частиц: стекло натриевое жидкое (ЖС) по ГОСТ 13078-82 «Стекло жидкое натриевое. Технические условия» производства ОАО «Контакт».

Технические характеристики жидкого стекла представлены в таблице 3. 
Технические характеристики жидкого стекла

\begin{tabular}{|l|c|}
\hline \multicolumn{1}{|c|}{ Наименование показателя } & Норма показателя \\
\hline Двуокиси кремния, \% & $21-24$ \\
\hline Окиси железа и окиси алюминия макс, \% & 0,25 \\
\hline Окиси кальция максимальное макс., \% & 0,2 \\
\hline Серного ангидрида макс, \% & 0,15 \\
\hline Окиси натрия, \% & $7,9-8,8$ \\
\hline Силикатный модуль, \% & $2,7-3,4$ \\
\hline Плотность, г $/$ см $^{3}$ & $1,28-1,34$ \\
\hline
\end{tabular}

Для создания арболитового блока полигональной формы с системой паз гребень (по принципу конструктора «LEGO») для лучшего заполнения формы-опалубки используется суперпластфикатор-С3 (ТУ 5745-001-97474489-2007). Обычно, данная химически-активная добавка используется в тяжелых бетонах для увеличения текучести бетонной смеси более чем в 5 раз, повышения прочности изделия, улучшения структуры бетона. В арболитовом же блоке полигональной формы добавка необходима для равномерного заполнения всего пространства опалубки, тем самым затвердевший, конечный продукт получается правильной формы, углы и грани ровные, равномерные, уменьшается усадка смеси.

Применение высокоэффективного Суперпластификатора С-3 в технологии изготовления арболитовой смеси обеспечивает:

1. По реологическим свойствам:

- улучшение удобоукладываемости, связности и однородности смеси;

- получение водоредуцирующего эффекта до 25\%;

- увеличение времени сохранения подвижности смеси на 1-1,5 ч.

2. По физико-механическим показателям:

- увеличение прочностных характеристик арболитобетона на $15 \%$ и более, относительно первоначального состава.

3. По технико-экономическим показателям:

- экономию вяжущего (цемент) на 15-20\% без снижения прочности материала;

- замену высокомарочного цемента на цемент с более низкой маркой; 
- сокращение энергетических затрат при тепло-влажностной обработке арболитобетона;

- снижение температуры изотермического прогрева на $10-15^{\circ} \mathrm{C}$;

- улучшение качества поверхности изделий, а также предотвращение высолообразования.

\section{Сиисок литературы}

1. Ламов И.В. Применение арболитовых блоков «LEGO» в малоэтажных жилых и производственных зданиях и сооружениях [Текст] / И.В. Ламов, М.А. Гончарова // Научные исследования: от теории к практике: Материалы V Междунар. науч.-практ. конф. (Чебоксары, 6 нояб. 2015 г.). В 2 т. Т. 2 / Редкол.: О.Н. Широков [и др.]. - Чебоксары: ЦНС «Интерактив плюс», 2015. №4 (5). - C. 47-50.

2. ТУ 5745-001-97474489-2007 Суперпластификатор «Пластификатор С-3» инструкция по применению.

3. Корнеев А.Д. Технология композиционной черепицы с теплоизоляцией из наполненного пенополиуретана / А.Д. Корнеев, М.А. Гончарова, Г.А. Шаталов // Строительные материалы. - 2014. - №4. - С. 92-95.

4. Гончарова М.А. Прогнозирование долговечности наполненного пенополиуретана в кровельной сэндвич-панели / М.А. Гончарова, Б.А. Бондарев, А.О. Проскурякова // Научный вестник ВГАСУ. Строительство и архитектура. 2014. - №3 (35). - C. 31-37.

5. Ламов И.В. Применение арболитовых блоков «LEGO» в малоэтажных жилых и производственных зданиях и сооружениях / И.В. Ламов, М.А. Гончарова // Научные исследования: от теории к практике: Материалы V Междунар. науч.-практ. конф. (Чебоксары, 6 нояб. 2015 г.). - Чебоксары, 2015. - С. 47-50.

6. Формирование систем твердения композитов на основе техногенного сырья / М.А. Гончарова, М.А. Чернышев // Строительные материалы. - 2013. №5. - C. 60-63. 
7. Разработка SIP-панелей для легковозводимых домов с повышенными теплотехническими свойствами / Г.С. Дедяев, М.А. Гончарова // Научные исследования: от теории к практике. - 2015. - Т. 2. - №4 (5). - С. 29-31.

Гончарова Маргарита Александровна - д-р техн. наук, доцент, заведующая кафедрой ФГБОУ ВО «Липецкий государственный технический университет», Россия, Липецк.

Goncharova Margarita Aleksandrovna - doctor of technical sciences, associate professor, head of the Department FSFEI of HE "Lipetsk State Technical University”, Russia, Lipetsk.

Проскурякова Анастасия Олеговна - канд. техн. наук, доцент ФГБОУ ВО «Липецкий государственный технический университет», Россия, Липецк.

Proskuryakova Anastasia Olegovna - candidate of technical sciences, associate professor FSFEI of HE “Lipetsk State Technical University”, Russia, Lipetsk.

Ламов Илья Владимирович - магистрант ФГБОУ ВО «Липецкий государственный технический университет», Россия, Липецк.

Lamov Ilya Vladimirovich - graduate student FSFEI of HE "Lipetsk State Technical University", Russia, Lipetsk.

Матченко Никита Александрович - магистрант ФГБОУ ВО «Липецкий государственный технический университет», Россия, Липецк.

Matchenko Nikita Aleksandrovich - graduate student FSFEI of HE "Lipetsk State Technical University", Russia, Lipetsk.

Дедяев Герман Сергеевич - магистрант ФГБОУ ВО «Липецкий государственный технический университет», Россия, Липецк.

Dyadev German Sergeevich - graduate student FSFEI of HE "Lipetsk State Technical University", Russia, Lipetsk.

Мирзабаев Руслан Рустамович - магистрант ФГБОУ ВО «Липецкий государственный технический университет», Россия, Липецк.

Mirzabaev Ruslan Rustamovich - graduate student FSFEI of HE "Lipetsk State Technical University”, Russia, Lipetsk. 